\title{
Automatic Judgment System for Chinese Retroflex and Dental Affricates Pronounced by Japanese Students
}

\author{
Akemi Hoshino and Akio Yasuda
}

\begin{abstract}
Chinese retroflex aspirates are generally difficult for Japanese students learning Chinese pronunciation. In particular, discriminating between utterances of aspirated dental and retroflex affricates is the most difficult for Japanese-speakers to learn. For the students' self-learning, the automatic judgment system was developed using a computer, so as to check the pronunciations by themselves. We extracted the features of correctly pronounced aspirated dental affricates

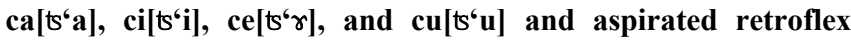

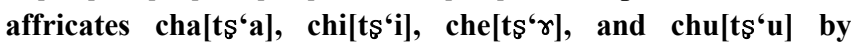
observing the spectrum evolution of breathing power during both voice onset time and voiced period of sounds uttered by $\mathbf{4 0}$ Chinese native speakers. We developed a 35-channel computerized filter bank to analyze the evolution of the breathing power spectrum by using MATLAB and then automatically evaluated the utterances of the 50 Japanese students. At the same time, we asked to native Chinese speakers to evaluate the same students' utterances for the reference. Our system rejected several samples that passed the screening by the native speakers. The success rates of the system were higher than $91 \%$ and $95 \%$ for aspirated retroflex and dental affricates, respectively.
\end{abstract}

Index Terms-Automatic pronunciation discrimination, Chinese aspirated retroflex and dental affricates, e-learning.

\section{INTRODUCTION}

Retroflex aspirates in Chinese are generally difficult for Japanese students learning Chinese pronunciation, because the Japanese language has no such sounds. In particular, discriminating between utterances with aspirated dental and retroflex affricates is difficult for Japanese-speakers to learn. We observed a classroom of native-Japanese-speaking students of Chinese uttering aspirated retroflex sounds modeledon the examples uttered by a native Chinese instructor. These utterances were generally not produced correctly; many of them sounded like dental affricates to the instructor, which implies that students could notcurl their tongues enough to articulate correctly, because there is no retroflex sounds in Japanese affricates.

In order to check the pronunciationsof students for self-learning using a personal computer, we need to establish the criteria for the correctly pronounced syllables.

Wehave previously [1]-[5] shown that breathing power

Manuscript received July 25, 2013; revised November 11, 2013. This work was supported in part by the Japan Society for the Promotion of Science under Grant 23501127

Akemi Hoshino is with Toyama National College of Technology, 1-2 Ebie, Neriya, ImizuCity, Toyama, 933-0293 Japan (e-mail: hoshino@ nc-toyama.ac.jp).

Akio Yasuda is with Tokyo University of Marine Science and Technology, 2-1-3 Etchujima, Koto-ku, Tokyo, 135-8533 Japan (e-mail: yasuda@kaiyodai.ac.jp). during voice onset time(VOT) is a useful measure for evaluating the correct pronunciation of Chinese aspirates. We also developed an automatic evaluation system [6], [7] for the utterances of students pronouncing Chinese aspirated affricates in accordance with the two parameters of VOT and breathing power during VOT.

Although there are several research reports on retroflex sounds [8], [9], developing report on the self-learning system of Chinese aspirated dental and retroflex affricates by CAI does not exist.

In order to develop the system to discriminate between retroflex and dental affricates automatically, we extracted the features of correctly pronounced aspirated dental affricates

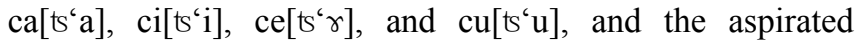

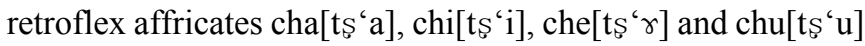
[10] by analyzing the spectrum of breathing power during VOT of sounds uttered by native Chinese speakers. For this purpose, we developed a computerized, 35-channel frequency filter bank. We found that the main difference between aspirated dental and retroflex affricates appeared in the spectrogram of breathing power during VOT [11].

To improve the discrimination of these affricates, we extracted the features of correctly pronouncing aspirated dental and retroflex affricates by analyzing the frequency spectrum of breathing power both during VOT and inside the voiced period of sounds, and established improved evaluation criteria on this basis. Below, we discuss the results in terms of how successfully they discriminate between aspirated dental and retroflex affricates pronounced by Japanese students.

We will continue to improve our pronunciation learning system by applying it to other Chinese aspirated affricates.

The Chinese in this paper is Standard Chinese and/or Modern Standard Chinese (Putonghua), based on the Beijing dialect.

\section{DifFERENCE BETWEen AsPiRATEd DENTAL AFFriCATE AND ASPIRATED RETROFLEX AFFRICATES}

The affricate is a complex sound generated by simultaneously articulating explosive and fricative sounds as one sound with the same point of articulation.

In this section, we define the distinctive feature that discriminates between the dental affricate $\left[\mathrm{t}^{\circ}\right]$ and retroflex one $\left[\mathrm{t}_{\mathrm{s}}{ }^{6}\right]$ by examining the spectrogram of the pairs ca[ts $\left.\mathrm{a}\right]$ -

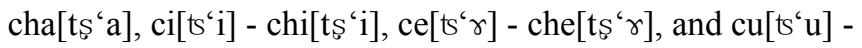
$\mathrm{chu}\left[\mathrm{ts}_{\mathrm{s}}{ }^{\mathrm{c}} \mathrm{u}\right]$ uttered by a native Chinese speaker.

Fig. 1 shows the temporal evolution of spectrograms of the aspirated retroflex sound cha[ts $\left.{ }_{s}{ }^{\prime} \mathrm{a}\right]$ (left) and the aspirated dental sound ca[ts'a] (right) uttered by a Chinese speaker. The 
lower part of the figure shows the waveform of the voltage evolution as picked up by a microphone. The ordinate, extended upward, shows the frequency component and the shade of the stripes, implying the approximate power level at the respective times and frequencies. The aspirate appears in the brief interval at the right of the spectrogram of ca[ts'a], indicated by the light, thin vertical stripes during VOT, between the stop burst and the onset of vocal fold vibrations followed by a vowel sound. This time interval is called the VOT [12], [13], in this case it is long, $160 \mathrm{~ms}$. Although slightly darker stripes appear between 2500 and $5000 \mathrm{~Hz}$ and 70 and $150 \mathrm{~ms}$, the temporal variation in breathing power during VOT is not significant.

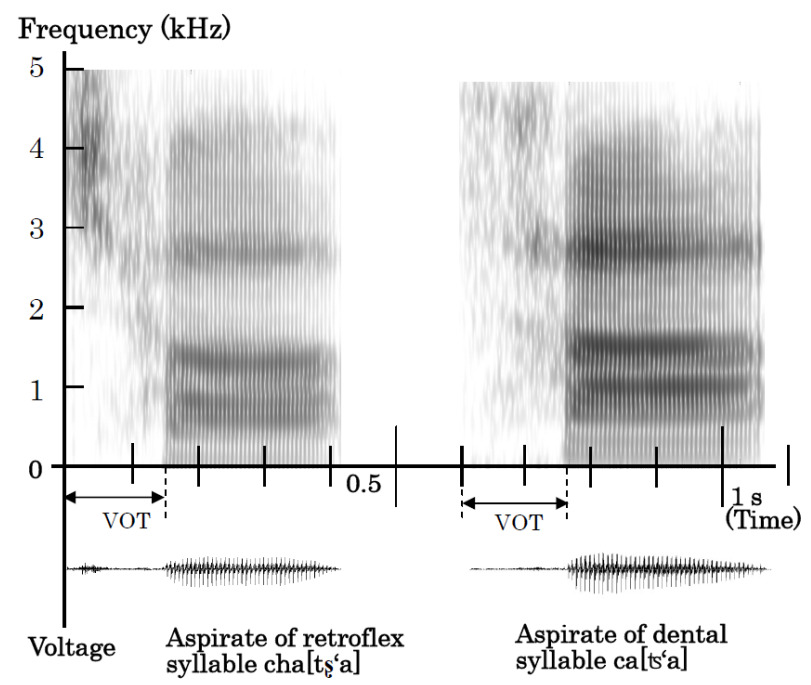

Fig. 1. Spectrograms of retroflex aspirate affricate cha[t $\left.\mathrm{t}^{\circ} \mathrm{a}\right]$ (left) and dental aspirated affricate ca['a] (right) pronounced by Chinese speaker.

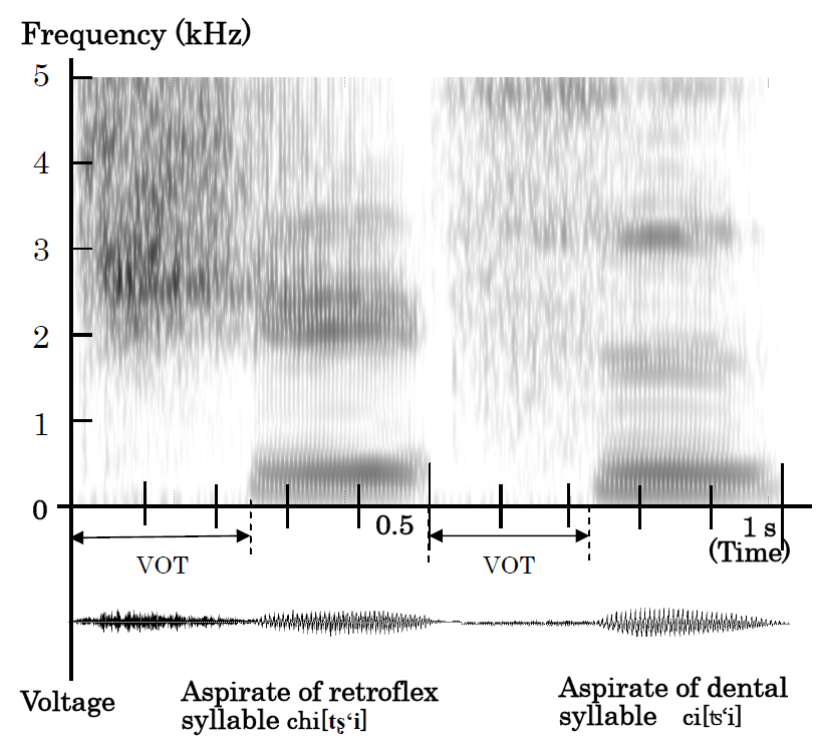

Fig. 2. Spectrograms of retroflex aspirate affricate chi[t $\left.{ }^{\circ} \mathrm{i}\right]$ (left) and dental aspirated affricate ci['i] (right), pronounced by a Chinese speaker.

The left spectrogram represents the aspirated retroflex sound cha[ts $\left.{ }^{\prime} a\right]$ as uttered by a Chinese speaker. The VOT was long, $150 \mathrm{~ms}$. The dark vertical stripes in the upper left were observed between 2500 and $5000 \mathrm{~Hz}$ in frequency, during $0-70 \mathrm{~ms}$ of VOT. This is caused by friction of airflow during breath release, arising at a spot between the curled tongue and the posterior alveolar ridge. The large amount of energy that builds up in the mouth dissipates at an early stage of VOT and generates a large amount of breathing power there.

The thick horizontal bands in the voiced period on the right part of the spectrogram represent the formants that help listeners discriminate between the three dental affricates. The criteria for discrimination are discussed later.

Fig. 2 shows the temporal variation in the spectrograms of the aspirated retroflex sound chi[ts $\left.{ }^{6} \mathrm{i}\right]$ (left) and the aspirated dental sound ci[ts'i] (right), uttered by a Chinese speaker. The VOT of the aspirated dental sound ci[ts'i] was long, $225 \mathrm{~ms}$, as seen on the right. The uniform and rather light colored vertical bands show that breathing power was rather steady during VOT.

The left spectrogram shows the aspirated retroflex sound chi[ts $\left.{ }^{i} i\right]$. VOT was long, $250 \mathrm{~ms}$. Throughout almost the entire VOT, dark vertical stripes were observed in the frequencies between 2000 and $5000 \mathrm{~Hz}$. This is due to friction at the breath release, which arises at a spot between the curled tongue and the posterior alveolar.

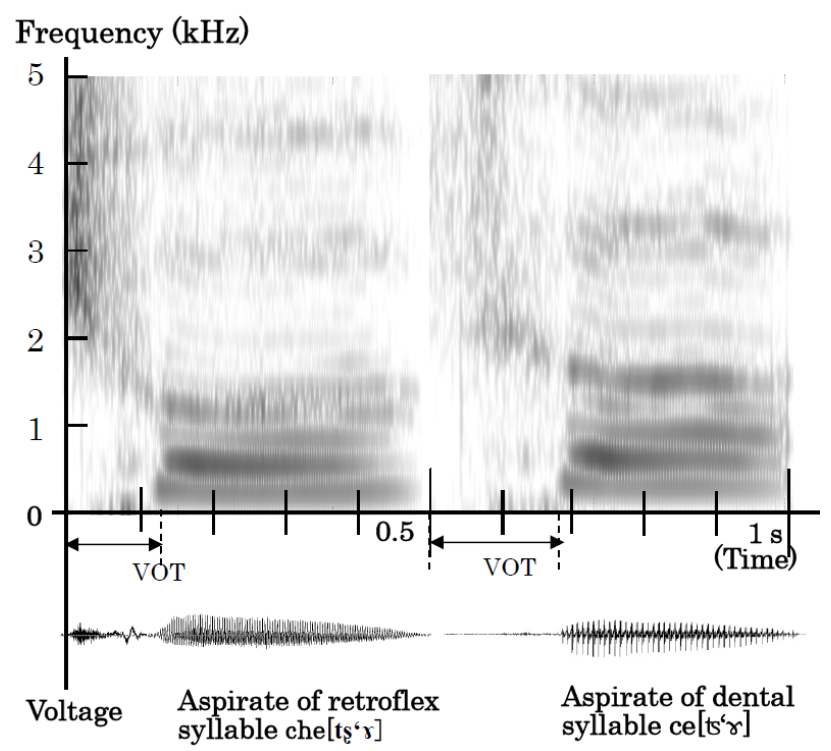

Fig. 3. Spectrograms of retroflex aspirate affricate che[ $\left.\mathrm{t}^{\circ}\right]$ (left) and dental aspirated affricate ce[']] (right) pronounced by a Chinese speaker.

Fig. 3 shows the temporal variation in the spectrograms of the aspirated retroflex sound che[ts $\left.{ }^{6} \gamma\right]$ (left) and the aspirated dental sound ce[ts $\gamma$ ] (right) as uttered by a Chinese speaker.

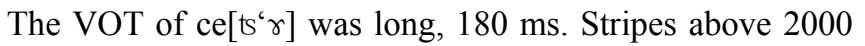
$\mathrm{Hz}$ are darker and imply slightly stronger breathing power there.

For the frequencies lower than $1200 \mathrm{~Hz}$ in the VOT, the vertical stripesare light indicating weak breathing power. The distinctive feature of retroflex aspirated affricates is non-uniform frequency and spectra during VOT, whereas aspirated dental ones have a rather uniform spectrum, as compared to the rather uniform spectrum for aspirated dental affricates, shown in the right spectrogram.

Fig. 4 shows the temporal evolution of spectrograms of the aspirated retroflex sound chu[ts $\left.{ }^{6} \mathrm{u}\right]$ (left) and the aspirated dental sound $\mathrm{cu}\left[\mathrm{ts}^{\mathrm{c}} \mathrm{u}\right]$ (right) as uttered by a Chinese speaker. The VOT of cu[ts'u] was long, $185 \mathrm{~ms}$, as seen on the right. Stripes above $1300 \mathrm{~Hz}$ are darker, implying slightly stronger breathing power there. Although darker stripes appear between 0 and $300 \mathrm{~Hz}$ frequency and from 80 to $120 \mathrm{~ms}$ VOT, 
the temporal variation in breathing power across VOT as a whole is not significant. The left spectrogram is for the aspirated retroflex sound chu[ts $\left.{ }^{6} \mathrm{u}\right]$. VOT is long, $190 \mathrm{~ms}$. Dark vertical stripes are observed between 3500 and $5000 \mathrm{~Hz}$ in frequency and from 0 to $160 \mathrm{~ms}$ VOT. They are caused by friction of breath during breath release, arising at a spot between the curled tongue and posterior alveolar position.

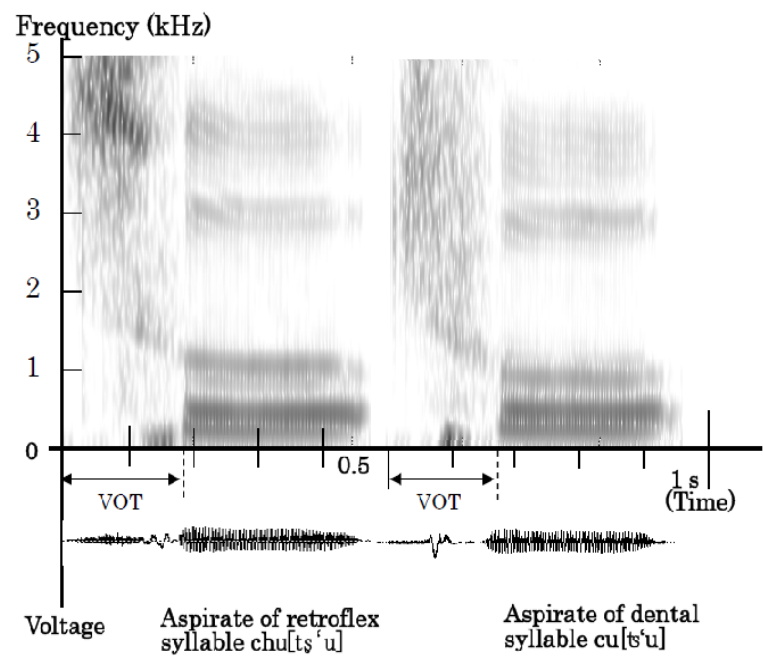

Fig. 4. Spectrograms of retroflex aspirate affricate chu[t $\left.t^{t} u\right]$ (left) and dental aspirated affricate $\mathrm{cu}[$ ' $\mathrm{u}]$ (right) pronounced by a Chinese speaker.

\section{Automatic MeAsurement of VOT AND BREATHING POWER}

We have shown that correct utterance of retroflex and dental aspirated affricates is closely related to the frequency spectrum in the VOT period.

Previously, we have developed an automatic measurement system for VOT and breathing power using a personal computer containing a 35-channel frequency filter bank, designed with MATLAB, in which the center frequency ranges from 50 to $6850 \mathrm{~Hz}$ with a bandwidth of $200 \mathrm{~Hz}$ [6], [7].We can extract the spectral features of aspirated retroflex and dental affricates in both VOT and voiced periods.

\section{A. VOT Measurement Algorithm}

We automatically detected the onset of the plosive release or burst. Pronounced signals were introduced into the filter bank and split to power at each center frequency every $5 \mathrm{~ms}$. The start time of VOT, $\mathrm{t} 1$, was determined by comparing powers for adjacent time frames when the number of temporally increasing channels is the maximum. The end of the VOT, $t 2$, was the start point of the formant. Thus, $t 2-t 1$ is defined as VOT.

In Section II above, we described the features of correct pronunciation of Chinese aspirated dental and retroflex affricates by observing temporal variation of breathing power spectra during VOT. Powers at each of the 35 channels were checked every $5 \mathrm{~ms}$ with $11.025 \mathrm{kHz}$ sampling, in accordance with the frequency criteria defined for VOT.

\section{B. Breathing Power Measurement Algorithm}

Average power during VOT is defined as follows. Power is deduced every $5 \mathrm{~ms}$ and are referred to as $\mathrm{Pi}, \mathrm{j}$, which means the power at $j \times 5 \mathrm{~ms}$ of the channel $\mathrm{i}(1-35)$, where $P i$ is the integration of the power at each interval for VOT of the channel $i$, as shown in Equation (1).

$$
P_{i}=\sum_{j=1}^{J} P_{i, j}\left(t_{j}\right) .
$$

Thus the energy, $W i$, of the channeli- is defined as

$$
W_{i, V O T}=P_{i} \times 5 \mathrm{~ms} .
$$

The average power, $P i, a v$, of each frequency channel during VOT is defined as

$$
P_{i, a v}=W_{i, V O T} / V O T
$$

Finally, average power, $P v i, a v$, at channel i in the voiced period, Tvs, can be defined similarly, as

$$
P v_{i, a v}=W_{i, v s} / T_{v s} \text {. }
$$

\section{Automatic Evaluation Procedure}

\section{A. Parameters for Discrimination}

We extracted the features of correctly pronounced Chinese

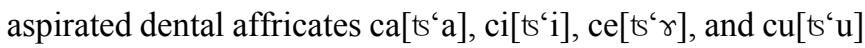
and aspirated retroflex affricates cha[t $\left.\mathrm{s}^{\prime} \mathrm{a}\right]$, chi[ $\left.\mathrm{t}_{\mathrm{s}}{ }^{\prime} \mathrm{i}\right]$, che[ $\left.\operatorname{ts}_{\varsigma^{6}}{ }^{\gamma}\right]$, and chu[t $\mathrm{s}^{6} \mathrm{u}$ ] by observing the spectrum evolution of breathing power during VOT and voiced period of sounds uttered by 40 Chinese native speakers.

TABLE I: EVALUATION CRITERIA ON UTTERANCE OF RETROFLEX ASPIRATED AFFRICATES

\begin{tabular}{ccccc}
\hline Syllable & Channels $(\mathrm{CH})$ & Frequency domain(Hz) & VOT range & Ave.Power in VOT \\
\hline cha[ts'a] & $\mathrm{CH} 15 \sim \mathrm{CH} 29$ & $2750 \sim 5750$ & $0 \sim \mathrm{VOT} / 2$ & 17 or more \\
chi[ts'i] & $\mathrm{CH} 10 \sim \mathrm{CH} 32$ & $1750 \sim 6350$ & Whole VOT & 25 or more \\
che[ts 'r] & $\mathrm{CH} 07 \sim \mathrm{CH} 30$ & $1150 \sim 5950$ & $0 \sim \mathrm{VOT}^{*} 2 / 3$ & 34 or more \\
chu[ts'u] & $\mathrm{CH} 17 \sim \mathrm{CH} 31$ & $3250 \sim 6150$ & $0 \sim \mathrm{VOT}^{*} 2 / 3$ & 11 or more \\
\hline
\end{tabular}

TABLE II: EVALUATION CRITERIA FOR FORMANTS OF RETROFLEX AFFRICATES DURING VOICED PERIOD AFTER VOT

\begin{tabular}{|c|c|c|c|}
\hline Syllable & $\mathrm{Fl}(\mathrm{Hz}) /(\mathrm{CH})$ & $\mathrm{F} 2(\mathrm{~Hz}) /(\mathrm{CH})$ & $\mathrm{F} 3(\mathrm{~Hz}) /(\mathrm{CH})$ \\
\hline$c a\left[t^{\prime} a\right]$ & $750 \sim 950 /(\mathrm{CH} 5)$ & $1150 \sim 1350 /(\mathrm{CH} 7)$ & $2150 \sim 2350 /(\mathrm{CH} 12)$ \\
\hline $\operatorname{ci}\left[\mathrm{t}^{\prime} \mathrm{i}\right]$ & $150 \sim 350 /(\mathrm{CH} 2)$ & $1350 \sim 1550 /(\mathrm{CH} 8)$ & $2550 \sim 2750 /(\mathrm{CH} 14)$ \\
\hline $\operatorname{ce}\left[\mathbf{t}^{6} r\right]$ & $350 \sim 550 /(\mathrm{CH} 3)$ & $1150 \sim 1350 /(\mathrm{CH} 7)$ & $2350 \sim 2550 /(\mathrm{CH} 13)$ \\
\hline$c u\left[t^{\prime} u\right]$ & $150 \sim 350 /(\mathrm{CH} 2)$ & $750 \sim 950 /(\mathrm{CH} 5)$ & $2550 \sim 2750 /(\mathrm{CH} 14)$ \\
\hline
\end{tabular}

\begin{tabular}{cccc}
\hline Syllable & $\mathrm{F1}(\mathrm{Hz}) /(\mathrm{CH})$ & $\mathrm{F} 2(\mathrm{~Hz}) /(\mathrm{CH})$ & $\mathrm{F} 3(\mathrm{~Hz}) /(\mathrm{CH})$ \\
\hline cha[ts'a] & $550 \sim 750 /(\mathrm{CH} 4)$ & $950 \sim 1150 /(\mathrm{CH} 6)$ & $1750 \sim 1950 /(\mathrm{CH} 10)$ \\
chi[ts'i] & $150 \sim 350 /(\mathrm{CH} 2)$ & $1950 \sim 2150 /(\mathrm{CH} 11)$ & $2750 \sim 2950 /(\mathrm{CH} 15)$ \\
che[tș'r] & $350 \sim 550 /(\mathrm{CH} 3)$ & $950 \sim 1150 /(\mathrm{CH} 6)$ & $2350 \sim 2550 /(\mathrm{CH} 14)$ \\
chu[tș'u] & $150 \sim 350 /(\mathrm{CH} 2)$ & $750 \sim 950 /(\mathrm{CH} 5)$ & $2750 \sim 2950 /(\mathrm{CH} 15)$ \\
\hline
\end{tabular}

TABLE III: EVALUATION CRITERIA FOR FORMANTS OF DENTAL AFFRICATES DURING VOICED PERIOD AFTER VOT

Table I and Table II respectively list the evaluation criteria for retroflex aspirated affricates and those in the voiced period after VOT, which depend on the values of F1, F2, and F3. If the power was higher than 17 between $2750 \mathrm{~Hz}$ (CH15) and $5750 \mathrm{~Hz}(\mathrm{CH} 29)$ averaged between the beginning of the 
VOT and1/2 of VOT, and if high power appears between 550 and $750 \mathrm{~Hz}, 950$ and $1150 \mathrm{~Hz}$, and 1750 and $1950 \mathrm{~Hz}$, the utterances are judged to be aspirated retroflex affricate cha[ts'sa].

If power is higher than 25between $1750 \mathrm{~Hz}(\mathrm{CH} 10)$ and $6350 \mathrm{~Hz}(\mathrm{CH} 32)$ throughout VOT in Table I, and high power appears between 150 and $350 \mathrm{~Hz}, 1950$ and $2150 \mathrm{~Hz}$, and 2750 and $2950 \mathrm{~Hz}$ in Table 2, the utterances are judged to be aspirated retroflex affricate chi[ts $\left.{ }^{\prime} \mathrm{i}\right]$.

If power was higher than 34 at frequencies between 1150 $\mathrm{Hz}(\mathrm{CH} 7)$ and $5950 \mathrm{~Hz}(\mathrm{CH} 30)$ averaged between the beginning of VOT to $2 / 3$ of VOT in Table 1 , and high power appears between 350 and $550 \mathrm{~Hz}, 950$ and $1150 \mathrm{~Hz}$, and 2350 and $2550 \mathrm{~Hz}$ in table 2, the utterances are judged to be aspirated retroflex affricate $\operatorname{che}\left[\mathrm{ts}_{\mathrm{s}}{ }^{\prime} \gamma\right]$.

If power is higher than 11 at frequencies between $3250 \mathrm{~Hz}$ $(\mathrm{CH} 17)$ and $6150 \mathrm{~Hz}(\mathrm{CH} 31)$ averaged between the beginning of VOT to $2 / 3$ of VOT in Table I, and high power appears between 150 and $350 \mathrm{~Hz}, 750$ and $950 \mathrm{~Hz}$, and 2750 and $2950 \mathrm{~Hz}$ in Table II, the utterances were judged to be aspirated retroflex affricate $\mathrm{chu}\left[\mathrm{t} \mathrm{s}^{\mathrm{c}} \mathrm{u}\right]$.

When the distinctive feature does not appear during the VOT period, we refer to Table III, which lists the evaluation criteria for dental aspirated affricates, namely, the values of F1, F2, and F3. If high power appears between 750 and $950 \mathrm{~Hz}, 1150$ and $1350 \mathrm{~Hz}$, and 2150 and $2350 \mathrm{~Hz}$, the utterances are judged to be aspirated dental affricate ca[ts'a]. If it appears between 150 and $350 \mathrm{~Hz}, 1350$ and $1550 \mathrm{~Hz}$, and 2550 and $2750 \mathrm{~Hz}$, they are judged to be aspirated dental affricate ci[ts'i]. If it appears between 350 and $550 \mathrm{~Hz}, 1150$ and $1350 \mathrm{~Hz}$, and 2350 and $2550 \mathrm{~Hz}$, they are judged to be aspirated dental affricate ce[ts $\gamma]$. Finally, if it appears between $150 \mathrm{~Hz}$ and $350 \mathrm{~Hz}, 750$ and $950 \mathrm{~Hz}$, and 2550 and $2750 \mathrm{~Hz}$, they are judged to be aspirated dental affricate $\mathrm{cu}\left[\mathrm{ts}^{6} \mathrm{u}\right]$.

\section{B. Automatic Evaluation and Results}

We tried to discriminate between the pronunciations of

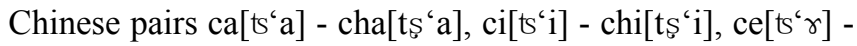

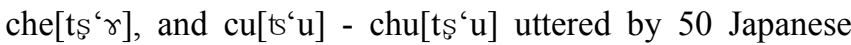

students.

Fig. 5 illustrates the flow of our system for the automatic discrimination of these aspirated retroflex and dental affricates pairs. In step 1, the uttered sounds are input to the computer. In step 2, the sounds are automatically analyzed using our 35-channel filter bank to create a data-base of temporal variation of the power spectra. In step 3, VOT is deduced using the algorithm described in subsection III.A.

In step 4 , the average power, $P i, a v$, is automatically calculated for each channel during VOT, as described in subsection III.B. In step 5, if any distinctive features are found during VOT, the sample is tentatively judged to be aspirated retroflex affricates and differentiated from others by referring to Table I and Table II.

If the utterance fulfills both conditions above, it is successfully identified as one of the four retroflex. Otherwise it is judged not to be a retroflex.

If a sample, judged to be non-retroflex in step 5, fulfills the conditions listed in Table III, it is successfully identified as one of the four aspirated dental affricates. Otherwise it is not judged to be one.

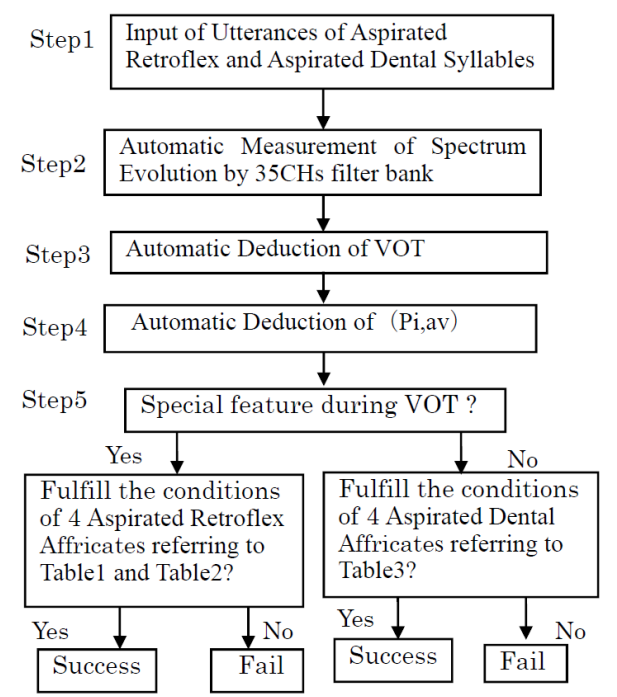

Fig. 5. Discrimination diagram of aspirated retroflex anddental affricate.

TABLE IV: NUMBER OF CORRECTLY JUdGED STUDENT'S PRONUNCIATIONS AMONG 50 ONES By NATIVE CHINESE SPEAKER AND OUR JUDGMENT SYSTEM

\begin{tabular}{|c|c|c|c|c|c|c|c|c|}
\hline & \multicolumn{4}{|c|}{ Aspirated retroflex syllables } & \multicolumn{4}{|c|}{ Aspirated dental syllables } \\
\hline & cha[ts'a] & chi[ts $\left.{ }^{i} \mathrm{i}\right]$ & che[ts' $\gamma]$ & $\mid$ chu[tş'u] & ca[ts'a] & ci[ts'i] & ce[ts'r] & cu[ts'u] \\
\hline $\begin{array}{l}\text { Number of correctly judged ones } \\
\text { by native Chinese speakers (1) }\end{array}$ & 38 & 41 & 32 & 35 & 44 & 42 & 38 & 39 \\
\hline $\begin{array}{l}\text { Number of correctly judged ones } \\
\text { by our judgment system (2) }\end{array}$ & 36 & 40 & 30 & 32 & 44 & 40 & 37 & 37 \\
\hline Correct judgment ratio (2)/(1) & $94 \%$ & $97 \%$ & $93 \%$ & $91 \%$ & $100 \%$ & $95 \%$ & $97 \%$ & $95 \%$ \\
\hline
\end{tabular}

Table IV lists the numbers of correctly judged utterances out of 50 students' data of aspirated retroflex affricates

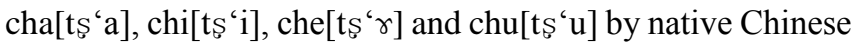
speakers were $38,41,32$, and 35 , respectively. However, those by our judgment system were $36,40,30$, and 32 , respectively.

50 Japanese students were those who had studied Chinese for 3 hours per week for 6 months. They all just followed Standard Chinese or Modern Standard Chinese(Putonghua), the dialects are not contained. All selected 9 native Chinese speakers were raised in Beijing, China. 6 of them are teachers in Chinese for the foreigners at the universities in Beijing. 3 are teachers in Japan. They can speak the exact Standard Chinese(Putonghua). The acceptance or rejection of these data is not affected by dialect pronunciation.

Some of the data which passed the native Chinese screening test were rejected due to its strict discrimination criteria. The ratios of correct judgment by our system and by 
native Chinese for aspirated retroflex affricates were $94 \%$,

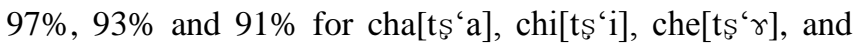
chu[ts $\left.{ }^{\prime} \mathrm{u}\right]$, respectively.

The numbers of correctly judged utterances out of 50 for aspirated dental affricates, ca[ts'a], ci[tsi], ce[ts' $\gamma]$ and $\mathrm{cu}\left[\mathrm{ts}^{\mathrm{c}} \mathrm{u}\right]$ by native Chinese speakers were 44, 42, 38, and 39, respectively, and those by our judgment system were 44, 40, 37 , and 37, respectively. The ratios of correct judgments by our system to those by native Chinese speakers for aspirated retroflex affricates were $100 \%, 95 \%, 97 \%$ and $95 \%$, for $\mathrm{ca}\left[\mathrm{ts}^{6} \mathrm{a}\right]$, ci[ts'i], ce[ts' $\left.\mathrm{t}\right]$ and $\mathrm{cu}\left[\mathrm{ts}^{6} \mathrm{u}\right]$, respectively.

Again, some of the data which passed the screening test by the native Chinese were rejected by our system.

\section{CONCLUSION}

We have been studying instruction in the pronunciation of Chinese aspirated sounds, which are generally difficult for Japanese students to perceive and reproduce. We closely examined spectrograms of these sounds uttered by native Chinese speakers and by Japanese students and determined criteria for their correct pronunciations of various aspirated sounds [1-5]. We had previously developed an automatic system for measuring and calculating VOT and the power during VOT of student pronunciations [6], [7].

In this paper, in order to develop the self-learning system of Chinese aspirated dental and retroflex affricates by CAI, we aimed at automatic distinction of the four pairs of aspirated dental and aspirated retroflex affricates ca[ts'a] -

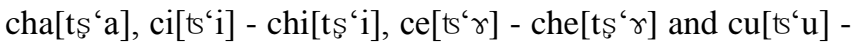
chu[t $\left.\mathrm{t}^{\mathrm{G}} \mathrm{u}\right]$. We automatically calculated the frequency spectra of these sounds during VOT and voiced periods and extracted the distinctive features of each sound. On that basis, we established criteria for automatically discriminating aspirated retroflex and dental affricates.

Next, we conducted an experiment on the automatic discrimination by our judgment system of 50 utterances by Japanese students. The results of the test showed that the system rejected some pronunciations which were judged to be correct by native Chinese speakers. However, the coincidences of the both judgments were $91 \%$ to $100 \%$ for the four pairs of retroflex and dental affricates.

We plan to apply our system to other samples of speech sounds to improve its performance.

\section{REFERENCES}

[1] A. Hoshino and A. Yasuda, "Evaluation of Chinese aspiration uttered sounds by Japanese students using vot and power (in Japanese),' Acoust. Soc.Jpn., vol. 58, no. 11, pp. 689-695, 2002.

[2] A. Hoshino and A. Yasuda, "The evaluation of Chinese aspiration sounds uttered by Japanese student using VOT and power," in Proc. the 2003 International Conference on Acoustics, Speech, and Signal Processing IEEE, Hong Kong, 2003, pp. 472-475.

[3] A. Hoshino and A. Yasuda, "Dependence of correct pronunciation of Chinese aspirated sounds on power during voice onset time," in Proc ISCSLP 2004, Hong Kong, 2004, pp. 121-124.

[4] A. Hoshino and A. Yasuda, "Effect of Japanese articulation of stops on pronunciation of Chinese aspirated sounds by Japanese students," in Proc. ISCSLP 2004, Hong Kong, 2004, pp.125-128.

[5] A. Hoshino and A. Yasuda, "Evaluation of aspiration sound of Chinese labial and alveolar diphthong uttered by Japanese students using voice onset time and breathing power," in Proc. ISCSLP 2006, Singapore, 2006, pp.13-24.

[6] A. Hoshino and A. Yasuda, "Pronunciation training system for Japanese students learning Chinese aspiration," in Proc. the 2nd International Conference on Society and Information Technologies(ICSIT), Orlando, Florida, USA, 2011, pp. 288-293.

[7] A. Hoshino and A. Yasuda, "Pronunciation Training System of Chinese Aspiration for Japanese Students," Acoustical Science and Technology, Japan, vol. 32, no. 4, pp. 154-157, July, 2011

[8] L. Zhou, H. Segi, and K. Kido, "The investigation of Chinese retroflex sounds with time-frequency analysis," The Acoustical Society of Japan, vol. 54 , no. 8 , pp. 561-567, 1998 .

[9] L. Zhou, H. Segi, and K. Kido, "The Investigation of Chinese Retroflex Consonants by Editing Synthesis Sounds with Phoneme," Reports of the 1998 autumn meeting the Acoustical Society of Japan, pp. 337-338, 1998.

[10] C. Zhu, Studying Method of the pronunciation of Chinese speech for foreign students (in Chinese), China: Yu Wu Publishing Co., pp. 145-151, 1997

[11] Hoshino and A. Yasuda, "Discrimination of Chinese pronunciations of aspirated dental and retroflex syllables according to breathing power and its frequency dependency during VOT," in Proc. Acoustics 2012, Nantes, France. pp. 339-344, April, 2012.

[12] R. D. Kent and C. Read, The acoustic analysis of speech, San Diego and London: Singular Publishing Group, Inc., 1992, pp. 105-109.

[13] C. Zhu, Studying method of the pronunciation of Chinese speech for foreign students (in Chinese), China: Yu Wu Publishing Co., pp. 63-71, 1997.

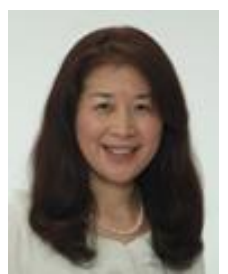

Akemi Hoshino was born in Shanghai, China on November 1, 1960. She received her Dr. Eng. degree from Tokyo University of marine science and technology of Japan in 2005. She belongs to Toyama national college of technology from 1997 until now.

She is currently an associate professor. "Evaluation of Chinese aspiration sounds uttered by Japanese students using VOT and power (in Japanese), Acoust. Soc.Jpn., vol. 58, no. 11, pp.689-695,(2002).

Her research interests are development of pronunciation training system of Chinese by CAI, and development computer-aided automatic judgment system, and Evaluation of Chinese aspiration sound uttered by Japanese Students based on VOT and power.

Dr. Hoshino is a member of Acoustical Society of Japan and Institute of Electronics, Information, Communication Engineers in Japan.

Akio Yasuda was born in Nagoya, Japan on April 6, 1943. He received MS (1968) and $\mathrm{PhD}(1975)$ from Nagoya University. He was a Research associate at Nagoya University in 1972. Since 1975, he joined at Tokyo University of Mercantile Marine as an associate professor.

He was awarded Emeritus Professor at Tokyo University of Marine Science and Technology in 2007.

$\mathrm{He}$ is presently majored in Satellite Navigation. Dr. Yasuda is a member of Acoustical Society of Japan, Institute of Electronics, Information, Communication Engineers in Japan, Japan Institute of navigation and Institute of Navigation. 